\title{
Study of environmental, social, and paternal factors in preterm delivery using sibs and half sibs. A population-based study in Denmark
}

\author{
Olga Basso, Jørn Olsen, Kaare Christensen
}

\begin{abstract}
Objective-The aim of this study was to evaluate the influence on preterm delivery of changes in putative genetic and environmental risk factors between two consecutive births. Low social status is a suspected risk indicator of preterm delivery, but the impact of social mobility has not been studied before.

Participants-The study uses national cohorts in which women act as their own controls. Subjects were identified by means of registries: 10455 women who gave birth to a preterm child and had a subsequent live birth between 1980 and 1992 and 9849 women who gave birth to a child after 37 completed weeks of gestation and had a subsequent live born child in the same time period formed the cohorts. Methods-The risk of having a premature infant in the subsequent pregnancy was analysed in each cohort as a function of changes in male partner, residency, occupation, and social status between the two pregnancies.

Results-There was a strong tendency to repeat a preterm delivery $(18 \% v 6 \%$ in the general population). Social decline was associated with a moderate increase in the recurrence risk (OR: 1.22 ; 95\% CI: 1.02 , 1.47). In the reference cohort the risk of preterm delivery associated with changing from a rural to an urban municipality was 2.03 (95\% CI: $1.14,3.64)$.

Conclusions-Social decline and moving to an urban municipality may be associated with preterm delivery.

(F Epidemiol Community Health 1999;53:20-23)
\end{abstract}

The Danish

Epidemiology Science

Centre at the

Department of

Epidemiology and

Social Medicine,

Aarhus University,

Høegh Guldbergsgade

10, DK 8000 Aarhus C,

Denmark

O Basso

J Olsen

Centre for Health and Social Policy, Odense University, Denmark K Christensen

Correspondence to: Dr O Basso.

Accepted for publication 18 August 1998
Genetic factors may, however, operate only through the maternal side. ${ }^{3}$

Previous spontaneous abortions, ${ }^{3}{ }^{713-15}$ previous induced abortions, ${ }^{1313}$ social factors, stress, race, infections, and several gynaecological conditions have been associated with preterm birth, ${ }^{1-3} 9$ 16-18 though there is no general consensus on some of these factors. $^{2} 3819$

A possible explanation for the association between spontaneous abortions and preterm delivery may be a high degree of HLA sharing between the partners, which is one of the hypotheses for recurrent spontaneous abortions. ${ }^{20} \mathrm{~A}$ similar hypothesis has been put forward for growth retardation. ${ }^{21}$ If the degree of HLA sharing plays a part in preterm birth, we would expect a decrease in recurrence of preterm delivery in mothers who change the male partner after having had a preterm infant. Changing residency or lifestyle is a life event that may cause stress and that may indicate changes in environmental factors of potential importance to the outcome of preterm delivery.

The aim of this study was to assess the risk of repeating a preterm delivery according to changes in the male partner or changes in social or environmental factors between the two pregnancies.

\section{Methods}

The data for this study were obtained from The Danish Medical Birth Registry and Statistics Denmark.

The Medical Birth Registry has registered all births in Denmark since 1973. From this source, 23580 new borns were identified as preterm deliveries in the time period from 1980 to 1992 and they represented all registered preterm deliveries by mothers who had at least two pregnancies.

The Fertility Database links populationbased registries on births, abortions, education, employment, and income. ${ }^{22}$ It includes information on all in the fertile age starting from the 1942 birth cohort.

Since 1968 all residents in Denmark are given a unique identification number (CPR), which was used to link data from the Medical Birth Registry to the Fertility Database, which provided information on parity of the mother, the biological father of each infant, and on occupational status at 1 January of the year in which the child was born.

From the 46920 pregnancies from mothers who had one or more preterm delivery we excluded all records with missing gestational 
Table 1 Characteristics of the study base and changes of potential determinants between the two prgnancies. Livebirths; Denmark, 1980-92

\begin{tabular}{|c|c|c|c|c|}
\hline & \multicolumn{2}{|c|}{ Exposed cohort ${ }^{\star}$} & \multicolumn{2}{|c|}{ Unexposed cohort } \\
\hline & Number & $\%$ & Number & $\%$ \\
\hline Preterm delivery & 1879 & 18.0 & 332 & 3.4 \\
\hline Partner status: changed & 1113 & 10.6 & 837 & 8.5 \\
\hline Unknown for any of the two births & 367 & 3.5 & 198 & 2.0 \\
\hline \multicolumn{5}{|c|}{ Type of municipality between the two pregnancies } \\
\hline Not changed & 8359 & 80.0 & 7858 & 79.8 \\
\hline Urban-urban & 1425 & 13.6 & 1391 & 14.1 \\
\hline Rural-rural & 78 & 0.7 & 70 & 0.7 \\
\hline Urban-rural & 337 & 3.2 & 323 & 3.3 \\
\hline Rural-urban & 256 & 2.4 & 207 & 2.1 \\
\hline Changed occupation & 4011 & 38.4 & 3750 & 38.1 \\
\hline \multicolumn{5}{|l|}{ Social mobility } \\
\hline No change & 7611 & 72.8 & 7028 & 71.4 \\
\hline Downward & 915 & 8.8 & 752 & 7.6 \\
\hline Upward & 1929 & 18.5 & 2069 & 21.0 \\
\hline \multicolumn{5}{|l|}{ Social status at index child } \\
\hline Low & 3266 & 31.2 & 2662 & 27.0 \\
\hline Middle & 4607 & 44.1 & 4291 & 43.6 \\
\hline High & 2582 & 24.7 & 2896 & 29.4 \\
\hline \multicolumn{5}{|l|}{ Age of the mother } \\
\hline$\leqslant 20$ & 278 & 2.7 & 171 & 1.7 \\
\hline $21-25$ & 2832 & 27.1 & 2302 & 23.4 \\
\hline $26-30$ & 4360 & 41.7 & 4471 & 45.4 \\
\hline $31-35$ & 2295 & 22.0 & 2330 & 23.7 \\
\hline$>35$ & 690 & 6.6 & 575 & 5.8 \\
\hline Total & 10455 & & 9849 & \\
\hline
\end{tabular}

* Exposed cohort: women whose index child was born after less than 37 completed weeks' gestation † Unexposed cohort: women whose index child was born after 37 or more completed weeks' gestation.

age $(n=702)$, and all multiple births and stillborn births $(n=3073)$. The exposed cohort consisted of all Danish women who gave birth to a live child after less than 37 completed weeks of gestation (index child) and to a subsequent liveborn baby between 1980 and 1992 (10 455 women). A 5\% random sample of the general population of women with two or more pregnancies in the same time period (the maximum number of records we could obtain from the National Board of Health) was processed in an analogous way: after excluding records with missing gestational age $(n=635)$ and multiple births and stillborn $(n=487)$, younger sibs of infants born at 37 or more completed weeks of gestation formed the unexposed cohort (9849 women).

The risk of preterm delivery following the index child was estimated as a function of the mother's status with respect to change in partnership, type of municipality (urban or rural), work sector, and social status between the two births. The comparisons were made within each cohort using couples without changes in any of the factors as the reference category.

Social status was categorised into three levels (low, middle, and high) according to the job held at the time of pregnancy, based upon a 10 point classification used by Statistics Denmark. The grouping was done before starting the analysis. The definition of the type of occupation was the short version based upon the International Standard Classification of Industries. ${ }^{23}$

The highest social status member of the couple determined the social status at each birth and, for non-cohabiting mothers, her social status was used. In the low social class the following categories were included: unemployed, retired, unskilled manual workers, and unspecified and unknown job levels. In the middle category were office workers, students, skilled manual workers, and those assisting the spouse. Finally, in the high category were all high ranking office workers, managers, self employed office workers, and small enterprise or shop owners.

Denmark has slightly over 5 million inhabitants and 276 municipalities: according to the municipality classification provided by Statistics Denmark, we coded municipalities as rural if $33 \%$ or less of the population lived in a city and we estimated the odds ratios according to changes in the type of municipality between the two births.

The described changes were examined in logistic regressions using dichotomised gestational age ( $<37$ completed weeks $) \geqslant 37$ completed weeks) as the outcome, adjusting for parity (second child/third or more), age of the mother ( $<20$ years, 21-25, 26-30, 31-35, $>35)$, interpregnancy interval ( $\leqslant 4.00$ months, 4.01-8.00 months, and >8.00 months), and social status of the couple at the time of birth of the index child. The analysis was also done for social status of each parent separately.

Midwives report whether the woman could recall the last menstrual period (LMP) before pregnancy as certain or not. Sub-group analyses were done for women whose LMP was reported as certain in both pregnancies $(\mathrm{n}=$ 6131).

Delivery before 37 completed weeks represents only one side of the distribution, and a paternal effect may be observable only by using the entire distribution of gestational age. We, therefore, used gestational age as a continuous variable by computing mean differences in gestational age between the two pregnancies in the unexposed cohort, for women who changed partner and women who did not according to the length of the index pregnancy. For these couples we computed partial correlation coefficients between the gestational age in the two pregnancies adjusted for initial social level.

\section{Results}

The proportion of preterm birth in the outcome pregnancy was $18 \%$ in the exposed cohort and $3.4 \%$ in the unexposed cohort. Couples in the exposed cohort were of lower social status, younger, changed partner more often, and improved social status less often (table 1).

Table 2 shows the adjusted odds ratios (OR) for preterm birth according to changes in partner, municipality, occupation, and social status between the two pregnancies. In the exposed cohort the only factor that was moderately associated with preterm delivery was decline of social status between the two pregnancies. The risk was present in couples who moved from middle to low social level between the two pregnancies. Social decline of the mother, rather than of the couple, was associated with an increased risk. The OR was 1.26 (95\% CI: $1.05,1.51)$ for mother driven downward social mobility and $0.96(95 \% \mathrm{CI}: 85,1.08)$ for father driven social decline.

In the unexposed cohort moving from a rural to an urban municipality was associated with an increased risk of preterm delivery. 
Table 2 Adjusted logistic regression for preterm delivery according to changes between the two pregnancies in male partner, municipality, type of job, and social status. Livebirths, Denmark, 1980-92

\begin{tabular}{|c|c|c|c|c|}
\hline \multirow[b]{2}{*}{ Factory } & \multicolumn{2}{|c|}{$\begin{array}{l}\text { Exposed cohort } \\
(n=10404 \ddagger)\end{array}$} & \multicolumn{2}{|c|}{$\begin{array}{l}\text { Unexposed cohort } t \\
(n=9803 \ddagger)\end{array}$} \\
\hline & $O R$ & $95 \% C I$ & $O R$ & $95 \% C I$ \\
\hline No changes & 1.00 & & 1.00 & \\
\hline Change of partner & 1.02 & $0.86,1.21$ & 1.18 & $0.80,1.72$ \\
\hline Partner unknown & 1.21 & $0.93,1.56$ & 1.04 & $0.48,2.27$ \\
\hline \multicolumn{5}{|c|}{ Change of municipality } \\
\hline Urban-urban & 0.88 & $0.75,1.03$ & 1.10 & $0.80,1.52$ \\
\hline Rural-rural & 1.03 & $0.59,1.83$ & 0.449 & $0.06,3.15$ \\
\hline Urban-rural & 0.95 & $0.71,1.26$ & 1.50 & $0.87,2.57$ \\
\hline Rural-urban & 0.90 & $0.64,1.25$ & 2.03 & $1.14,3.64$ \\
\hline Change of job & 0.99 & $0.89,1.10$ & 1.01 & $0.80,1.29$ \\
\hline \multicolumn{5}{|c|}{ Change of social status } \\
\hline Downward & 1.22 & $1.02,1.47$ & 1.04 & $0.67,1.62$ \\
\hline Upward & 1.01 & $0.87,1.16$ & 0.79 & $0.58,1.08$ \\
\hline
\end{tabular}

* Exposed cohort: women whose index child was born after less than 37 completed weeks' gestation. † Unexposed cohort: women whose index child was born after 37 or more completed weeks' gestation.

\pm The discrepancies in totals are because of missing values. $\$$ All odds ratios are adjusted for social status of the couple when the index child was born, age of the mother at birth of the current child, parity of the mother at the index child $(1,1+)$, interpregnancy interval $(<4$ months, $4-8$ months, else). I In this group there were 70 subjects, but only one case of preterm delivery.

Mothers with parity two at the outcome child had a similar OR associated with social decline (OR: 1.24; 95\% CI: 1.01, 1.53; $\mathrm{n}=7983$ ), while women with higher parity had an $\mathrm{OR}$ in the same direction, but lower $(\mathrm{OR}=$ 1.12; 95\% CI: $0.75,1.67 ; \mathrm{n}=2421$ ).

In the unexposed cohort, the risk associated with changing to an urban municipality was confined to women with parity higher than two (OR: 3.19; 95\% CI: 1.08, 9.41) and change of partner in this group was also associated with high risk (OR: $2.01 ; 95 \%$ CI: 1.04, 3.87). The total number of women in this subgroup was 1456 , of whom only 65 had a preterm delivery $(4.5 \%)$.

When the analysis was restricted to women whose LMPs in both pregnancies were reported as certain, we observed a stronger association between downward social mobility and preterm delivery in the exposed cohort (OR: 1.38; 95\% CI: 1.09, 1.74; $\mathrm{n}=6131$ ), as compared with the analysis in table 2 . No increase in risk was seen for very preterm delivery ( $<34$ completed weeks). The outcome pregnancies in the exposed cohort that had a gestational age lower than 34 weeks were 5.6\% versus $0.9 \%$ in the unexposed cohort.

The mean differences in gestational age between the pregnancy under study and the index pregnancy were computed according to the length of the previous pregnancy and partner status for the unexposed cohort. Table 3 shows the expected regression towards the mean and no substantial differences according

Table 3 Differences in mean gestational age (completed weeks) and standard deviation according to change of partner in the unexposed cohort. Stratified by previous gestational age of the index pregnancy (difference = gest outcome pregnancy-gest index pregnancy). Livebirths; Denmark, 1980-92

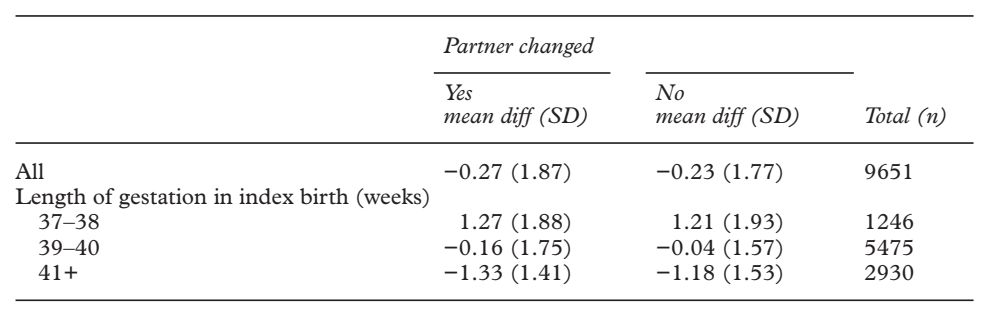

KEY POINTS

- Social decline is a moderate risk factor for the recurrence of preterm delivery.

- There is a strong tendency to repeat a preterm delivery $(18 \%)$.

- We found no sign of a paternal genetic effect on preterm delivery.

- Moving from a rural to an urban municipality may increase the risk of preterm delivery.

to change of partner was found. A higher correlation between the length of gestation in the two pregnancies was, however, seen for stable couples than for women who changed their partners between the two births $(0.26$ $(n=8814)$ and $0.19(n=837)$, respectively).

\section{Discussion}

The rationale behind the applied design is derived from the component causal model. ${ }^{24} 25$ By focusing on a pregnancy outcome driven cohort where all were, or had been, exposed to a sufficient set of causes of preterm delivery at enrolment, the risk of recurrence was estimated as a function of changes of potential determinants between two pregnancies. A cohort of mothers with no preterm delivery was, by definition, not exposed to a sufficient set of causes for that event. Changes between the two pregnancies in any of the recorded factors are thus predicted to lead to a higher risk of preterm delivery in the second birth if the factor is in the causal field.

In the exposed cohort $18 \%$ repeated a preterm delivery compared with $3 \%$ in the unexposed cohort, which confirms a previous preterm delivery as one of the strongest predictors. $^{136-8}$

A decline in social status was associated with a moderately higher risk of preterm delivery but only in the exposed cohort. Interruption of social network, as loss of social contact, may also be responsible for the risk associated with moving from a rural to an urban area, which, however, was only seen in the unexposed cohort.

Misclassification of gestational age is a possible source of bias and any factor that introduces random misclassification of gestational age will increase the proportion of preterm births without changing the average pregnancy duration in the population. This type of misclassification would include term births in the exposed cohort and preterm births in the unexposed cohort and thus dilute the contrast between the two cohorts.

Misclassification of the outcome birth could explain our findings if misclassification occurred more frequently in the group with downward social mobility, which did not seem to be the case. Restricting the analysis to pregnancies with reported certain LMPs strengthened the association, as expected when random misclassification is present.

Social mobility as a risk factor for preterm delivery has not been previously studied, though low social status has been extensively 
investigated with conflicting results. ${ }^{1-3} 1926-28$ The fact that downward social mobility was associated with preterm delivery only in the exposed cohort could imply that this group already was of poorer health, which could lead to a social decline and, if the disease in question (for example, diabetes) is associated with preterm delivery, this could explain the association. We expect, however, only few diseases to have this effect and serious diseases would, furthermore, tend to reduce fertility.

We have previously shown that downward social mobility is a moderately strong risk factor for low birth weight in women who had a normal weight child and, to a lesser degree, for women who previously had a low birth weight child $^{29}$; this is not unexpected as preterm delivery and low birth weight share some common causes. ${ }^{16}$

It has previously been shown that gestational age is correlated in different pregnancies within the same mother, ${ }^{10}$ which was also seen in our study. A slightly higher correlation coefficient was found in women who did not change partner in the unexposed cohort and we found a high $\mathrm{OR}$ associated with partner change in women with parity higher than two, which suggested that either paternal genes or stress related to partner change may play a part in timing the duration of gestation. Stress is a possible explanation, but it could be a chance finding because the effect was not seen in the exposed cohort.

Our results speak against a strong paternal effect on preterm delivery and on gestational age as such. They indicate that the uterine environment and/or maternal genetic factors are the most important determinants.

The results of this study, however, show that the studied factors had none or a weak effect on preterm delivery. These findings may be because of the fact that none of the putative factors under study was actually part of the causal field(s) for preterm delivery, or that we used too crude measures. Residual confounding or non-differential misclassification could also be partly responsible for the findings.

We did not have data to discriminate between subtypes of preterm deliveries (spontaneous, with or without premature rupture of the membranes, and induced) that may have aetiological heterogeneity. ${ }^{14}{ }^{30}$ As we excluded twins and stillborns, we are not likely to have a high proportion of induced preterm births, but a mixture of different types of preterm deliveries in our data could be a further reason for the lack of findings. ${ }^{28}$

The results supported, however, the hypothesis that life events or changes in living conditions play a part in the occurrence of preterm delivery.

Funding: the study was funded by The Danish Research Academy (jr no 1995-145-0057), Helsefond (jr no 11/277-95),
Fonden af 17-12-1981 (jr no 19054) and Kong Christian den Tiendes Fond (jr no 786695), Statens Sundhedsvidenskabelige Forskningsråd (jr no 12-1663-1). The activities of the Danish Epidemiology Science Centre are funded by a grant from the Danish National Research Foundation.

Conflicts of interest: none.

1 Kramer MS. Intrauterine growth and gestational duration determination. Pediatrics 1987;80:502-11.

2 Main DM. The epidemiology of preterm birth. Clin Obstet Gynecol 1988;31:521-32.

3 Berkowitz GS, Papiernik E. Epidemiology of preterm birth. Epidemiol Rev 1993;15:414-43.

4 Hack M, Merkatz IR. Preterm delivery and low birth weight. A dire legacy. N Engl F Med 1995; 333:1772-3.

5 Medicinsk fødselsstatistik 1993. Copenhagen: Sundhedsstatistikken, 1995:2.

6 Lang JM, Lieberman E, Cohen A. A comparison of risk factors for preterm labor and term small-for-gestational-age birth. Epidemiology 1996;7:369-76.

7 Keirse MJ, Rush RW, Anderson AB, et al. Risk of pre-term delivery in patients with previous pre-term delivery and/or abortion. Br f Obstet Gynaecol 1978;85:81-5.

8 Carr-Hill RA, Hall MH The repetition of spontaneous preterm labour. Br 7 Obstet Gynaecol 1985;92:921-8.

9 Mercer BM, Goldenberg RL, Das A, et al. The preterm prediction study: a clinical risk assessment system. Am f Obstet Gynecol 1996;174:1885-95.

10 Bakketeig L, Hoffman HJ, Harley EE. The tendency to repeat gestational age and birth weight in successive births. Am F Obstet Gynecol 1979;135:1086-103.

11 Magnus P, Bakketeig LS, Skjærven R. Correlations of birth weight and gestational age across generations. Ann Hum Biol 1993;20:231-8.

12 Neale MC, Cardon LR. Methodology for genetic studies of twins and families. Dordrecht: Kluwer Academic, 1992.

13 Pickering RM, Forbes JF. Risks of preterm delivery and small-for-gestational age infants following abortion: a population study. Br f Obstet Gynaecol 1985;92:1106-12.

14 Meis PJ, Michielutte R, Peters TJ, et al. Factors associated with preterm birth in Cardiff, Wales. II. Indicated and spontaneous preterm birth. Am f Obstet Gynecol 1995;173: 597-602.

15 Basso O, Olsen J, Christensen K. Risk of preterm delivery, low birthweight and growth retardation following spontaneous abortion: a registry-based study in Denmark. Int 7 Epidemiol 1998;27:642-6.

16 Ekwo EE, Gosselink CA, Woolson R, et al. Risks for premature rupture of amniotic membranes. Int f Epidemiol 1993; 22:496-503

17 Romero R, Mazor M. Infection and preterm labor. Clin Obstet Gynecol 1988;31:553-84.

18 Goldenberg RL, Iams JD, Mercer BM, et al. The preterm prediction study: the value of new vs. standard risk factors in predicting early and all preterm births. Am f Public Health 1998;88:233-8.

19 Stein A, Campbell EA, Day A, et al. Social adversity, low birth weight, and preterm delivery. BMF 1987:295:291-3.

20 Christiansen OB. Epidemiological, immunogenetic and immunotherapeutic aspects of unexplained recurrent miscarriage. Dan Med Bull 1997;44:396-424.

21 Verp MS, Sibul M, Billstrand C, et al. Maternal-fetal histocompatibility in intrauterine growth retarded and normal weight babies. Am F Reprod Immunol 1993;29:195-8.

22 Knudsen LB. The Danish Fertility Database. Dan Med Bull1998;45:221-5.

23 Danmarks Statistiks erhvervsgrupperingskode af 1 april 1977. 4. udgave. Copenhagen: Danmarks Statistik, 1986.

24 Parker JD, Schoendorf KC, Kiely JL. Associations between measures of socioeconomic status and low birth weight, small for gestational age, and premature delivery in the United States. Ann Epidemiol 1994;4:271-8.

25 Rothman KJ. Causes. Am f Epidemiol 1976;104:587-92, Am f Epidemiol 1995;141:90-5.

26 Olsen J, Schmidt MM, Christensen K. Evaluation of nature-nurture impact on reproductive health using half-siblings. The computerized square dance study design. Epidemiology 1997;8:6-11

27 Wildschut HIJ, Nas T, Golding J. Are sociodemographic factors predictive of preterm birth? A reappraisal of the 1958 British Perinatal Mortality Survey. Br f Obstet Gynaecol 1997;104:57-63.

28 Lumley J. How important is social class a factor in preterm birth? Lancet 1997;349:1040-1.

29 Basso O, Olsen J, Johansen AMT, et al. Change in social status and risk of low birth weight in Denmark: populationbased cohort study. BM7 1997;315:1498-502.

30 Savitz DA, Blackmore CA, Thorp JM. Epidemiologic characteristics of preterm delivery: etiologic heterogeneity. $\mathrm{Am}$ f Obstet Gynecol 1991;164:467-71. 